\title{
Channel Choice and Source Choice of Entrepreneurs in a Public Organizational Context: The Dutch Case
}

\author{
Jurjen Jansen, Lidwien van de Wijngaert, and Willem Pieterson \\ University of Twente, Center for e-Government Studies \\ P.O. Box 217, 7500 AE Enschede, The Netherlands \\ \{j.jansen, 1.vandewijngaert,w.pieterson\} @utwente.nl
}

\begin{abstract}
Most e-Government research focuses on citizens, the use and effects of electronic channels and services. However, businesses are an important target group for governmental agencies as well. Governmental agencies have a duty to inform businesses and to make this information easy to access. In order to increase accessibility it is important to closely relate to the behavior of users. Therefore, the purpose of the present investigation is to gain insight about the channel and source choice of entrepreneurs in a public organizational context. According to 323 entrepreneurs, who filled out an electronic questionnaire, the internet is the most preferred channel and a search engine is the most preferred source for obtaining governmental information. Business-, entrepreneur- and situational characteristics have, although small, effect on these choices.
\end{abstract}

Keywords: Channel choice, source choice, entrepreneurs, businesses, public service delivery, vignette method.

\section{Introduction}

Governmental agencies deliver services to both citizens and businesses. Given the complexities of many businesses it is likely that governmental agencies have more contacts with businesses than with citizens. However, most studies focusing on the use of (electronic) services and/or service channels [e.g. 1, 2-5] are aimed at citizens. It is questionable to what extent the results of studies among citizens are applicable to businesses. Businesses have more complex service interactions and the internet penetration among businesses is higher than among citizens. This, for example, has led to a mandatory electronic tax filing for business in the Netherlands [6]. However, it remains difficult for governmental agencies to reach businesses. Bergers [7], for example, states that governmental information, to a large extent, does not reach the entrepreneur. She states that too little is known about this target group as the most important reasons for this; a client-centered approach is missing.

In order to better direct information to entrepreneurs insight into the channel choice and source choice of entrepreneurs regarding public organizations needs to be obtained. This is the main focus of our paper. 


\section{Public Service Delivery to Businesses}

The relationship between governmental agencies and businesses is, in general, relatively complex. This complexity is driven by a number of aspects. First of all, there are more rules and regulations and more contact points as compared to the relationship between governmental agencies and citizens. Second, the playing-field is complex. Entrepreneurs do business with different kinds of (semi) public organizations. This means that public service delivery has a complex and networked nature. Third, the moments of contact are complex. In some cases public organizations have indirect contact with a business, i.e. through intermediaries. This means that some contacts are mediated and some are not. The fourth and last aspect of complexity is the business itself. In some cases the entrepreneur is the business, while in other cases this is the accountant or bookkeeper. The whole makes service delivery to businesses hard to optimize.

Illustrative for this complexity is the limited range of knowledge in this field [e.g. 8]. Not only is the amount of research regarding service delivery to businesses in sharp contrast with research regarding service delivery to citizens, it can also be questioned to what extent the insights about citizens can be applied to businesses.

Public organizations do, however, increasingly feel a need to adopt a more clientcentered approach [9]. According to Van Duivenboden and Lips [10] there are three explanations for this. First, changing expectations from businesses, second, a complex societal environment that calls for different ways of direction, and, third, a differentiating offer of public services by using ICTs. Furthermore, according to Jansen et al. [9] this is prompted by ongoing bureaucratic procedures and the increase of abstract and impersonal electronic services and also by society in general which is becoming more complex, dynamic and diverse.

This diversity [see, 9] is based on three types of characteristics, namely: business characteristics, entrepreneur characteristics, and situational characteristics. We believe that these characteristics are important predictors of channel and source choice.

\subsection{Business, Entrepreneur, and Situational Characteristics}

The first category of characteristics can be defined as demographics. Demographic segmentation holds that people who have the same demographics characteristics, e.g. age and gender, act the same [11].

According to Statistics Netherlands, the number of businesses in the Netherlands in 2008 was almost 800.000 . We have chosen to focus our study on small and medium enterprises (SMEs). SMEs, i.e. businesses with 1 - 49 employees, are by far the largest group of businesses in the Netherlands. According to Statistics Netherlands $98 \%$ of the businesses can be defined as SMEs.

Besides the demographic characteristics of businesses we also take a look at entrepreneur demographics. According to Statistics Netherlands over two-thirds of the entrepreneurs is male. Furthermore, the entrepreneurs are most found in the age groups 25 to 45 and 45 to 65 years. A small percentage of entrepreneurs is older than 65 and an even smaller percentage is 15 to 25 years. Conclusively, we take a look at the educational level of entrepreneurs. 
In addition, we focus on the psychographic characteristics of entrepreneurs. Cahill [12] defines psychographic segmentation as differentiation in activities, interests, opinions, and values. The Technology Acceptance Model, henceforth TAM [13] has been successfully validated by scholars who have tested the model empirically and found that it explained much of the variance between perceived usefulness and perceived ease of use, i.e. attitude, and adoption intentions [e.g. 14, 15-17]. Because of this, the TAM is regarded as a trustworthy tool for predicting the intention to adopt and use (new) technologies. We define attitude as attitude towards governmental information, i.e. the first psychographic characteristic.

Although attitude can be a useful predictor for behavior, we believe behavior can be better predicted by mapping what people actually do. Applying ICTs in service delivery processes is an obvious choice for most public organizations. However, it is not obvious that everyone can make proper use of these electronic services. According to Van Deursen and Van Dijk [18] four types of digital skills determine to what extend one can use these services. These skills are: operational skills, formal skills, information skills, and strategic skills. Although no numbers are known about the digital skills of entrepreneurs we believe that they, like citizens [18], have different skill levels. Therefore, digital skills are the second psychographic characteristics we include in our research.

The final type of characteristics is the situational characteristics. We believe that situational characteristics, often not included in behavior models, are important predictors of both channel and source choice $[19,20]$. In this paper we have defined five situational characteristics. The first one is topic. Entrepreneurs may visit different channels or make use of different sources considering the topic. Important and often searched for topics by entrepreneurs are about: starting a new business, personnel, housing, environment, tax, innovation, transaction, and rules and regulations.

The other situational characteristics we define are: type of need, i.e. need to know versus nice to know; level of importance, i.e. high versus low; type of knowledge, i.e. orientation versus specific; and level of urgency, i.e. high versus low.

\subsection{Channel Choice and Source Choice}

Informing businesses can be done through different service channels. Pieterson et al. [19, p.9] define a channel as “...an access point by which organizations and clients can have contact with each other". According to these researchers channels are used to communicate with clients, facilitate clients with purchases, and offer clients products or services. For this research we define three channels: internet, telephone, and service desk.

Besides channels, entrepreneurs have a whole range of sources to choose from. Based on cluster analysis (see chapter 3), we define five main categories of sources. The main sources are: search engines, portals, governmental agencies, expert organizations, and the personal network of the entrepreneurs.

\subsection{Conclusion}

In sum, we expect that four groups of factors influence the choice of channels and sources by entrepreneurs, i.e. business characteristics (business size), entrepreneur 
demographics (age, gender and education), entrepreneur psychographics (attitude towards governmental information), and situational characteristics (subject, type, importance, type of knowledge and urgency).

Using a quantitative study, we will try to answer the question what channels and sources entrepreneurs choose to obtain governmental information and how the four groups of factors affect these choices.

\section{Method}

The research model provides an overview of the variables that were included in this research project. In the online questionnaire questions were posed regarding personal characteristics such as age and gender, preferences for channels and sources. To assess how different situational characteristics affect channel and source choices, we have used a vignette method (see below). Before the questionnaire was put online it was pretested by three researchers and six entrepreneurs.

In the questionnaire, respondents were presented with a list of fifteen different sources of information from which they could choose to search for information. In order to reduce complexity we used hierarchical clustering. Using an Euclidean distance as a measure of closeness and furthest neighbor to cluster the sources we distinguished five sources of information as presented in section 2.3.

The research population concerned all SMEs in the Netherlands. In order to reach this group we made use of an online panel of a commercial market research company. The panel consisted of 8000 possible respondents.

The questionnaire could be filled in from the beginning of October till the beginning of December in 2009. A relative long period was needed in order to receive enough respondents. In December, an effective response of $4 \%(\mathrm{~N}=323)$ was reached. This low response can be partly explained by the selection criteria. Of the 953 people who accessed our survey 538 did not meet the proper conditions to participate. Despite the low response rate, the final sample provides an adequate representation of the Dutch population of entrepreneurs. Female entrepreneurs are well represented with $35 \%$. The mean age of the respondents is 42 . Entrepreneurs with higher education levels are slightly over-represented, while the different kinds of company sizes are well represented.

\subsection{The Vignette Method}

This research method is also referred to as factorial surveys, vignette studies, policy capturing and conjoint measurement. These methods offer similar, yet more or less unrelated approaches in marketing and product development research and have been around for some time [20]. The methods borrow and adapt the concept of manipulation from the experimental tradition. From the survey tradition they borrow the greater richness of detail and complexity that characterizes real-life circumstances [22]. The basic idea is to present people with contrived hypothetical situations. These situations, scenarios, vignettes or cases are developed by combining characteristics of 
possible situations as described in the research model. This can be explained the easiest by using an example:

Suppose... You are thinking about starting a new business. You know there are a number of legal obligations need to be fulfilled. You have not yet looked into the matter but would like to look for some information. Where and how will you search for information?

In this hypothetical situation the subject is starting a new business. Furthermore, the situation can be characterized as need to know, orientation and non-urgent. In total, respondents were presented with eight of such situations. Other cases, for example, do not outline a general situation, as above, but also more specific situations in which an entrepreneur has a specific question about a particular scheme.

\subsection{Scales and Analysis}

The following table shows an overview of the measures used in the study:

Table 1. Variables and measures

\begin{tabular}{|c|c|}
\hline Variable & Measure/Description \\
\hline \multicolumn{2}{|l|}{ Business demographics } \\
\hline size & Number of employees of the firm \\
\hline \multicolumn{2}{|c|}{ Entrepreneur demographics } \\
\hline Age & Age of the respondent \\
\hline Gender & Gender of the respondent \\
\hline Education & Highest level of education of the respondent \\
\hline \multicolumn{2}{|l|}{ Entrepreneur psychographics } \\
\hline Attitude & Attitude of the respondent towards governmental information \\
\hline Digital skills & Self assessed level of digital skills \\
\hline \multicolumn{2}{|l|}{ Situational characteristics } \\
\hline Subject & $\begin{array}{l}\text { Starting a new business, personnel, housing, environment, } \\
\text { tax, innovation, transaction, and rules and regulations }\end{array}$ \\
\hline Type & Need to know or nice to know \\
\hline Importance & High or low importance of the issue \\
\hline Type of knowledge & Specific or general (orientation) knowledge \\
\hline Urgency & High or low urgency \\
\hline
\end{tabular}

Data are analyzed in different ways. In order to group the different sources we used a cluster analysis using the Ward method [23]. We have used (multi-nominal) logistic regression in order to analyze the impact of the (dichotomous) situational characteristics on channel and source selection and regular (OLS) regression to assess the impact of the other variables.

\section{Results}

We used a number of items to measure the attitude towards the government. Six items, related to the quality of governmental information were presented to respondents. These 
items showed a homogeneous picture with a Cronbach's Alpha of 0.84. The average score on each of the items ranged between four and five on a seven point scale, which means that respondents in general were relatively positive about the quality of governmental information.

Similarly, digital skills were measured using four items that expressed different levels of digital skills [18]. Analysis of homogeneity resulted in a Cronbach's Alpha of 0.78. In general, respondents expressed a relatively high level of digital skills with scores between five and six on a seven point scale.

\subsection{Channel Choice}

The first objective was to gain more insight in the channel choice of entrepreneurs. We asked the respondents what the probability is of choosing each channel. We have done this both directly, i.e. by self-reports (figure 1a), and indirectly, by asking them what they would choose based on the vignettes (figure $1 \mathrm{~b}$ ).

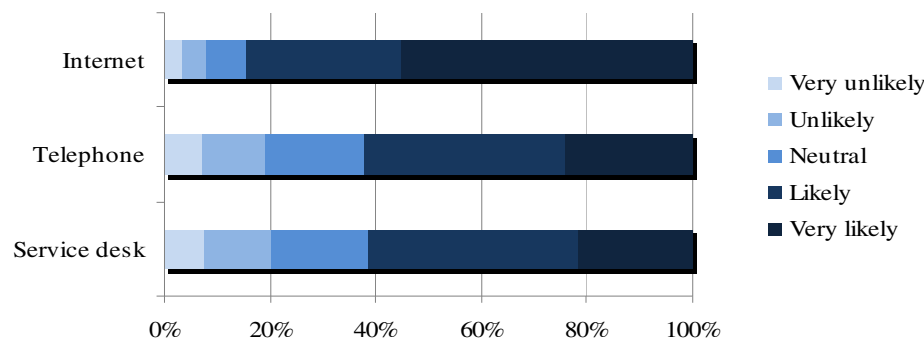

Fig. 1a. Reported probability of use

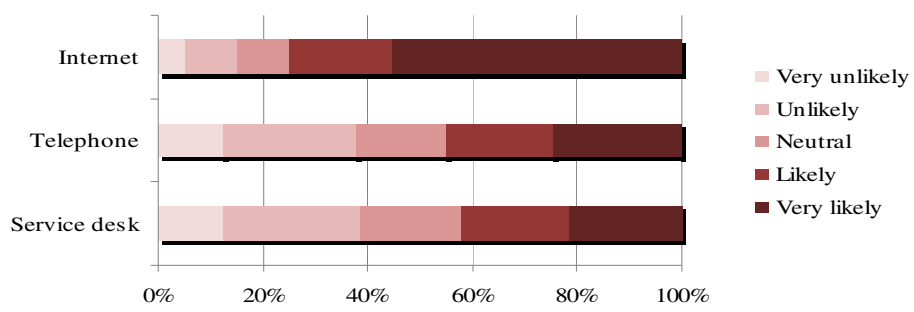

Fig. 1b. Probability of use based on the vignettes

What can be seen from the figures above is that the reported probability differs from the probability based on the vignettes. In general, the internet channel is the most preferred channel. A large majority uses this channel on a monthly basis or more frequent. The preferences for telephone and service desk score lower, especially in the vignettes. About $50 \%$ never visits the service desk and $40 \%$ just a few times a year. Besides this, entrepreneurs turn out to be real multi-channelers. On average, the respondents make use of three different channels. About one-third has used four channels in 2009. 
Regarding the demographic characteristics of businesses we see that larger businesses have a small favor for the telephone compared to internet and service desk. Concerning the demographic characteristics of entrepreneurs we observed two significant results (see the left side of table $2 \mathrm{a}$ in the annex). Older entrepreneurs tend to choose the internet channel more often than younger entrepreneurs and male entrepreneurs make more use of the telephone than female entrepreneurs. No significant results were found regarding the service desk. This could imply that the service desk is a suitable channel for everyone.

The psychographic characteristics show also some variation. An increase of the digital skills has a significant effect on the choice of all three channels. This is the highest for the internet channel. Entrepreneurs with a positive attitude towards governmental information also have a preference for internet.

The topics of the vignettes are no great predictor of channel choice. The preference for the service desk, however, shows the most variation. The preference for this channel is the strongest with the topics about personnel and starting a business. The other characteristics of the vignettes do not or hardly influence channel choice. Only small differences were found considering the service desk. When the vignettes dealt with low importance and orientation issues, entrepreneurs slightly, but significantly preferred the service desk as a channel to get information (see the left side of table $2 b$ in the annex).

\subsection{Source Choice}

The second objective was to gain more insight in the source choice of entrepreneurs. In this section we discuss the relationship between the choices for a specific source based on the characteristics of the vignettes that were presented to the respondents.

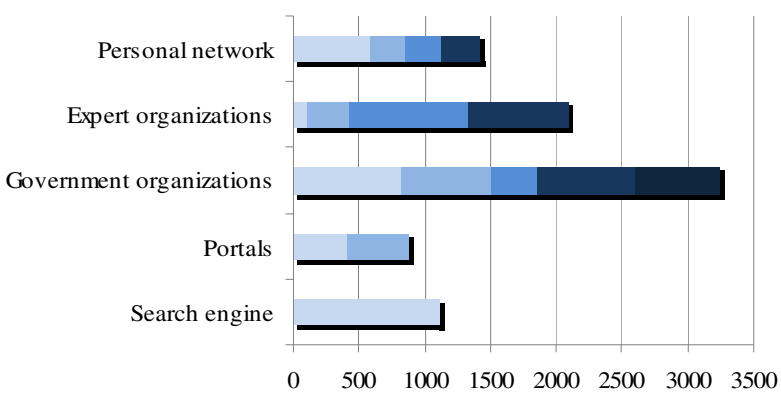

Fig. 2. Source choices of entrepreneurs

Figure 2 shows the number of times that a specific source was mentioned for a specific topic. Most source clusters contain multiple sources. For example, the personal network consists of external advisors, family and friends, internal colleagues, and external colleagues. The search engine is the most used source for searching public information. Also expert organizations, e.g. chamber of commerce and professional associations are important as well as government organizations, like national government and municipalities. 
Regarding the demographic characteristics of businesses we conclude from the right side of table $2 \mathrm{a}$ in the annex that larger businesses make less use of expert organizations and more use of their personal network as compared to smaller businesses. Concerning the demographic characteristics of entrepreneurs we see that older entrepreneurs use government and expert organizations as a source for information. Younger entrepreneurs rather consult their personal network. Female, and higher educated entrepreneurs consult expert organizations more often as a source for information than male and lower educated entrepreneurs.

The psychographic characteristics show also some variation. Entrepreneurs with a high level of digital skills significantly use search engines and consult government organizations more often than entrepreneurs with less digital skills. When entrepreneurs have a negative attitude towards governmental information, they make significantly more use of their personal network compared to entrepreneurs with positive attitudes towards governmental information.

On the right side of table $2 b$ in the annex it is demonstrated that search engines and portals are used most when entrepreneurs are in need for specific information. Government organizations are accessed in cases of high importance as well as for specific purposes. Expert organizations are consulted when the importance is high and when urgency is high. The personal network is addressed when the importance is high and when entrepreneurs are seeking information about specific issues. Furthermore, we found that search engines and portals are used for all topics. Moreover, portals are used a little less often than search engines as a starting point. Also, entrepreneurs gather information from expert organizations relatively often when the topic is about starting a new business, personnel and tax issues. Government organizations are approached most often when the topics are about environment, transactions, or rules and regulations issues.

\section{Conclusion and Discussion}

The goal of this study was to gain insight in which channels and which sources entrepreneurs use for public information. In order to reach this goal an online questionnaire was presented to Dutch entrepreneurs containing a vignette method. In total, 323 respondents have fully completed the questionnaire. Based on the response rate and the difficulty to achieve this, we conclude that entrepreneurs are a hard to reach target group for research. Especially immigrant entrepreneurs were difficult to reach with a presence of $3 \%$. Nonetheless, considering the drawbacks of the respondents, they do form a realistic reflection of the entrepreneurial target group. However, the study is limited to the Dutch context and little can be said if the findings would remain valid in other national and cultural contexts.

This brings us to the first research question: which channels and which sources do entrepreneurs use regarding public organizational information? Based on the results we can conclude the following:

1) Entrepreneurs have chosen internet as the most preferred channel to obtain governmental information. Nevertheless, this does not imply that other channels are not used. Therefore, government organizations should still follow multi-channel strategies. This finding is, however, not really surprising. Perhaps the internet as a channel should have been differentiated in different possibilities, like e-mail and chat. 
2) Based on the self-reports, entrepreneurs have a strong preference for the internet channel when they are orientating themselves, when they want to know something fast, and when they want to know things about rules and regulations. On the other hand, when they want to know things about which has high importance or about a specific topic, they prefer the telephone or service desk.

3) Based on the vignettes, entrepreneurs still have a strong preference for the internet channel, but the differences are smaller. Surprisingly, the opposite seems to be unfolding. For orientation questions entrepreneurs seem to prefer the service desk. This contradiction can be explained by differentiating between intentional behavior and actual behavior. Whereas self-reports, by stating propositions, reflect intentional behavior, vignettes do a better job in portraying actual behavior.

In the seventies and eighties of the last century scholars believed in the rational model of channel choice. This model was based on the Media Richness Theory [24] and the Social Presence Theory [25]. This model implies that people think rational about their channel choice, based on the characteristics of the channels and the characteristics of the question they have. However, as noted by the Social Influence Model [26] and the Channel Expansion Theory [27], these choices can also be influenced by unconscious variables. This is supported by research of Pieterson [19] who developed a framework for the channel choice of citizens. One of the main predictors in his model is habit.

In the case of the vignettes, entrepreneurs likely revert to their habits, than when asked to think about their behavior. Thus, the vignettes give a more realistic picture of the reality. However, there is a price to pay. Although the situational characteristics have some influence, the explained variance is low. This could, however, be caused by the design of our vignettes. Therefore, a more precise description of different situations should be considered.

4) Regarding the sources, entrepreneurs have a strong preference for search engines like Google to obtain governmental information. However, government organizations as well as expert organizations and to a smaller extent portals can also be considered among the most important sources for searching information. It seems that entrepreneurs rely more on their own skills to obtain governmental information than to obtain it via portals. The question is if this is the most efficient way. When searching for governmental information via portals it is more certain that all relevant information is obtained. Perhaps entrepreneurs should be educated about this? An additional point of discussion is that no attention is paid to traditional offline sources, like telephone books.

The second research question was: to what extent do the four groups of factors affect the channel and source choice of entrepreneurs regarding public organizational information? Based on the results we can conclude the following:

1) Larger businesses make use more of the telephone channel and less of the internet and service desk. Furthermore, they make more use of their personal network and less of expert organizations compared to smaller businesses.

2) Older entrepreneurs make use of the internet channel the most and have more contact with governmental and expert organizations. We expected that younger entrepreneurs would make more use of the internet. A possible explanation for this is that they are well aware of the drawbacks of the internet and therefore make use of 
the telephone. Younger entrepreneurs are consulting their personal network more often. Male entrepreneurs make more use of the telephone. Female and higher educated entrepreneurs make more use of consulting expert organizations.

3) When entrepreneurs have a positive attitude towards government information they tend to use the internet more often. Entrepreneurs with a more negative attitude are getting their information from their personal network. When the digital skills of entrepreneurs increase, the preference for all the other channels increases as well, especially for the internet channel. Digital skilled entrepreneurs also make more use of search engines and consult governmental organizations more often.

4) Conclusively, the situational characteristics are no great predictor of channel choice. However, it does have some effect on source choice. Entrepreneurs who are in need for specific information have a strong preference for using search engines and portals. When the information is necessary for specific and highly important topics, governmental agencies are accessed. Expert organizations are addressed when the importance is high and when urgency is high. The personal network is consulted when the importance is high and when entrepreneurs are seeking information about specific issues.

Our study is amongst the first to analyze channel and source choice behavior among businesses. In line with studies among citizens we see that businesses use different channels for different purposes in different situations. However we lack theories that describe or predict how these situational characteristics affect channel and source choice. The variables used in this study might help in building such a theory.

The added value of this research is that it shows that it is possible to explain channel and source choice from situational characteristics in stead of only asking respondents their preferences, e.g. ease of use and perceived usefulness. However, we need to understand more clearly what it is exactly in these situations that explain certain types of behavior. Future research should focus on this.

\section{References}

1. Pieterson, W.: Channel Choice; Citizens' Channel Behavior and Public Service Channel Strategy. Faculty of Behavioural Sciences, PhD. University of Twente, Enschede, 302 (2009)

2. Pieterson, W., Ebbers, W.: The Use of Service Channels by Citizens in the Netherlands: Implications for Multi-Channel Management. International Review of Administrative Sciences 74 (2008)

3. Reddick, C.G.: Citizen-Initiated Contacts with Government: Comparing Phones and Websites. Journal of E-Government 2, 27-53 (2005)

4. Reddick, C.G.: Citizen Interaction with E-Government: From the Streets to Servers? Government Information Quarterly 22, 38-57 (2005)

5. Thomas, J.C., Streib, G.: The New Face of Government: Citizen-Initiated Contacts in the Era of E-Government. Journal of Public Administration Research and Theory 13, 83 (2003)

6. Ebbers, W., Pieterson, W., Noordman, H.: Electronic Government: Rethinking Channel Management Strategies. Government Information Quarterly 25, 181-201 (2008) 
7. Bergers, A.M.: Communicatie met Ondernemers in het MKB: Een Handreiking voor Communicatie-adviseurs van de Rijksoverheid (Communication with SME Entrepreneurs: Assistance for Communication Advisors of the Federal Government) (2003),

http: / /www. communicatieplein.nl/

dsc?c=getobject\&s=obj\&objectid=143472 (retrieved March 9, 2008)

8. Sadowski, B.M., Maitland, C., van Dongen, J.: Strategic Use of the Internet by Small- and Medium-Sized Companies: An Exploratory Study. Information Economics and Policy 14, 75-93 (2002)

9. Jansen, J., de Vries, S., van der Geest, T., Arendsen, R., van Dijk, J.A.G.M.: The state of client-centered public service delivery in the netherlands. In: Wimmer, M.A., Scholl, H.J., Janssen, M., Traunmüller, R. (eds.) EGOV 2009. LNCS, vol. 5693, pp. 293-304. Springer, Heidelberg (2009)

10. van Duivenboden, H., Lips, M.: CRM in de Publieke Sector: Naar een Klantgerichte Elektronische Overheid (CRM in the Public Sector: Towards a Client-Centered Electronic Government). Holland Management Review 85, 45-57 (2002)

11. Fu, J.-R., Chao, W.-P., Farn, C.-K.: Determinants of Taxpayers' Adoption of Electronic Filing Methods in Taiwan: An Exploratory Study. Journal of Public Information 30, 658-683 (2004)

12. Cahill, D.J.: Lifestyle Market Segmentation. Haworth Press, New York (2006)

13. Davis, F.D.: Perceived Usefulness, Perceived Ease of Use, and User Acceptance of Information technology. MIS Quarterly 13, 319-339 (1989)

14. Adams, D.A., Nelson, R.R., Todd, P.A.: Perceived Usefulness, Ease of Use, and Usage of Information Technology: A Replication. MIS Quarterly 16(2), 227-246 (1992)

15. Szajna, B.: Empirical Evaluation of the Revised Technology Acceptance Model. Management Science 42(1), 85-92 (1996)

16. Venkatesh, V., Davis, F.D.: A Theoretical Extension of the Technology Acceptance Model: Four Longitudinal Field Studies. Management Science 46(2), 186-204 (2000)

17. Venkatesh, V., Morris, M.G., Davis, G.B., Davis, F.D.: User Acceptance of Information Technology: Toward a Unified View. MIS Quarterly 27(3), 425-478 (2003)

18. van Deursen, A.J.A.M., van Dijk, J.A.G.M.: Improving Digital Skills for the Use of Online Public Information and Services. Government Information Quarterly 26, 333-340 (2009)

19. Pieterson, W.: Channel Choice: Citizens Channel Behavior and Public Service Channel Strategy. University of Twente, Enschede (2009)

20. Van de Wijngaert, L., Bouwman, H.A.: Multi-Theory Approach Towards the Adoption, Use and Effects of IT-Services. In: Vishwanath, A., Barnett, G. (eds.) Advances in the Study of the Diffusion of Innovations: Theory, Methods, and Applications (forthcoming)

21. Pieterson, W., Teerling, M., Klievink, M., Lankhorst, M., Janssen, M., Boekhoudt, P.: Multichannel Management: De Stand van Zaken. Multi-Channel Management: State of the Art. Novay, Enschede (2007)

22. Rossi, P.H., Nock, S.S.: Measuring Social Judgments: The Factorial Survey Approach. Sage, Beverly Hills (1982)

23. Ward, J.: Hierarchical Grouping to Optimize an Objective Function. Journal of the American Statistical Association 58, 236-244 (1963)

24. Daft, R.L., Lengel, R.H.: Information richness: A new approach to managerial behavior and organizational design. In: Cummings, L.L., Staw, B.M. (eds.) Research in organizational behavior, vol. 6, pp. 191-233. JAI Press, Homewood (1984)

25. Short, J., Williams, E., Christie, B.: The social psychology of telecommunications. John Wiley, London (1976) 
26. Fulk, J., Schmitz, J., Steinfield, C.W.: A social influence model of technology use. In: Fulk, J., Steinfield, C.W. (eds.) Organizations and communication technology. Sage Publications, London (1990)

27. Carlson, J.R., Zmud, R.W.: Channel expansion theory and the experiential nature of media richness perceptions. The Academy of Management Journal 42(2), 153-170 (1994)

\section{Annex}

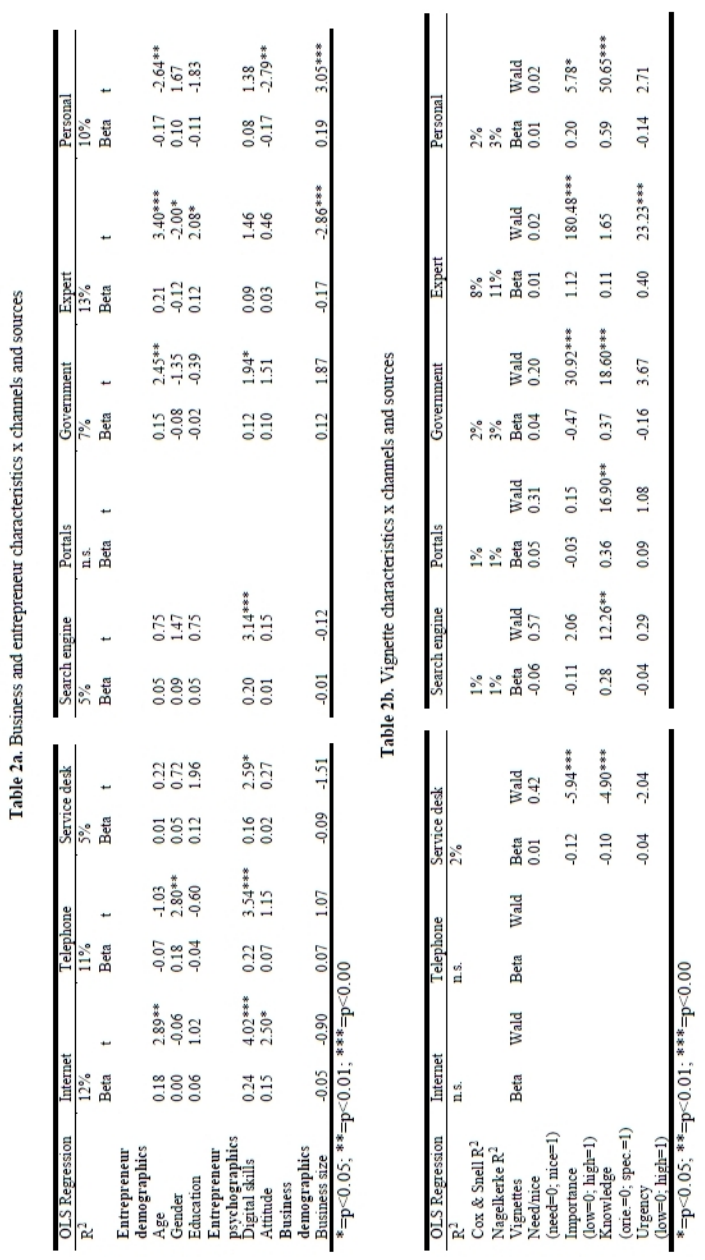

